\title{
Effect of wood type and thickness on acetification kinetics in traditional vinegar production
}

\author{
This article was published in the following Dove Press journal: \\ International Journal of Wine Research \\ 18 April 2009 \\ Number of times this article has been viewed
}

\author{
Maria-Jesús Torija' \\ Estibaliz Mateo' \\ Carlos-Alfredo Vegas' \\ Carla Jara' \\ Angel González' \\ Montse Poblet' \\ Cristina Reguant ${ }^{\prime}$ \\ Jóse-Manuel Guillamon² \\ Albert Mas' \\ 'Biotecnología Enológica. \\ Departament de Bioquímica i \\ Biotecnologia, Facultat d'Enologia, \\ Universitat Rovira i Virgili, \\ Tarragona, Spain; ${ }^{2}$ Departamento \\ de Biotecnología de los Alimentos, \\ Instituto de Agroquímica y Tecnología \\ de Alimentos (CSIC), Burjassot, \\ València, Spain
}

Correspondence:Albert Mas

Departament de Bioquímica i

Biotecnologia, Facultat d'Enologia,

Universitat Rovira iVirgili, C/Marcel.lí

Domingo s/n, 43007 Tarragona, Spain

Tel +34977558688

Fax +34977558232

Email albert.mas@urv.cat

\begin{abstract}
Traditional vinegar production is a lengthy process which implies high operational risks and jeopardizes the organoleptic characteristics of the final product. In an effort to solve these problems without changing the traditional model, we modified the wood type and thickness of vinegar barrels. We acetified in triplicate in barrels made of acacia, cherry, chestnut, and oak and in three wood thicknesses $(15,20$, and $25 \mathrm{~mm})$ in two different vinegar plants. The operating volume was set at $60 \mathrm{~L}$. Reducing wood thickness improved neither maximum acetification velocity or the total length of the process, and in some cases even worsened them. The process took longer in oak barrels than in other types of wood barrel in one of the vinegar plants. Therefore, the choice of wood is a parameter to be considered in the wine vinegar production.
\end{abstract}

Keywords: acacia, cherry, chestnut, oak, acetic acid bacteria

\section{Introduction}

Wine vinegar is a wine by-product that has come to play an important role in salad dressings, ketchup and other sauces. From a technological point of view, there are two processes for vinegar production: the traditional or superficial method (slow, the best known is the Orleans method), and the submerged method (quick, different acetification devices). ${ }^{1,2}$ Traditional wine vinegar is made in wood barrels with the primary transforming microorganisms, acetic acid bacteria (AAB), placed on the surface of the wine substrate and therefore in contact with atmospheric air. ${ }^{2-4}$ The quantity of oxygen available for the $\mathrm{AAB}$ is therefore limited, resulting in a lengthy process. However, several processes take place during the long period in which the product is in contact with the wood cask. On one hand, a complex bacterial metabolism releases several secondary metabolites such as acetoin ${ }^{5}$ into the vinegar. Also, aging occurs at the same time as acetification, meaning that vinegars produced by means of this method take on a higher degree of organoleptic complexity. Finally, the lengthy process allows the compounds in the vinegar to more thoroughly blend. These products are therefore highly appreciated over submerged vinegars, and are sold at higher market prices. ${ }^{3,6,7}$ Nevertheless, the most serious threat to the survival of this sector is that this lengthy process entails several risks which considerably limit the production of these high-quality vinegars.

Wine and other beverages have traditionally been stored and aged in wood barrels. ${ }^{8}$ Much research has been done into the effect of wood barrels on wine quality, and the compound transfer and positive effects of wood, especially oak, is well established..$^{9-13}$ Meanwhile, as vinegar is generally considered to be a by-product associated with spoiled wine, little or no attention has been paid to which type of barrel is the most suitable for 
its production. Consequently, the wood barrels used for vinegar production tend to be handed down, having previously been used for wine aging. Such barrels are not the most appropriate for vinegar production because whereas vinegar production requires a higher degree of oxygen transfer, ${ }^{4}$ in wine aging high wood porosity is avoided to limit oxidation. ${ }^{14}$

It is well known that while vinegars are produced and aged in barrels, their volatile compounds are enriched mainly as a result of two important processes: they are concentrated as water is lost through the wood pores; and new compounds, such as esters, are formed. ${ }^{15,16}$ To date, oak is most frequently used in the aging of wines or vinegars ${ }^{17}$ although occasionally chestnut and more rarely acacia, cherry, or mulberry are also used. However, the influence of wood type on vinegar development - its kinetics and microbiology - has not yet been studied.

The differing porosities and chemical compositions of each type of wood may affect the development of the process and the resulting product. Empirical data collected suggest that mulberry has a higher porosity than other woods such as acacia, cherry, or chestnut, although the porosity of these last three is superior to that of oak. Higher porosity is related to higher oxygen diffusion and might therefore result in a quicker transformation of ethanol into acetic acid by AAB.

The aim of this work was to analyze different variables in an attempt to reduce the time needed for the production of traditional wine vinegar. To do this we tested two strategies for increasing oxygen transfer: (i) using barrels made of wood with different porosities and (ii) decreasing barrel thickness. We studied the effect of both parameters on the kinetics of the process, evaluating the time needed to complete acetification. The study was carried out in two vinegar plants using four different types of wood - cherry, chestnut and acacia with oak as the control - and three barrel thicknesses: 15 and $20 \mathrm{~mm}$ with a thickness of $25 \mathrm{~mm}$ as the control.

\section{Materials and methods}

The study was conducted in two vinegar plants: Viticultors Mas d'en Gil (MG, Bellmunt del Priorat, Tarragona, Spain) and La Guinelle (LG, Banyuls, France). There are differences between the two plants in terms of wine characteristics, climate, and the period of time each has been in operation. MG uses dry wine in their production process whereas LG uses sweet wine ( $70 \mathrm{~g}$ residual sugar/L). The MG plant is housed in a relatively cold, closed building whereas the LG plant is in the open air and subject to dramatic changes in temperature. Finally, LG had operated as a vinegar plant for five years prior to the study, whereas MG is a new vinegar plant (less than one year in production).
The barrels were constructed by Boteria Torner (Barcelona, Spain) and specifically designed for this experiment. Briefly, they had the typical design of $60 \mathrm{~L}$ barrels and were constructed in various thicknesses of 25 (standard thickness, used as control), 20 and $15 \mathrm{~mm}$. The woods selected were acacia, chestnut, cherry, and oak, the last of which was used as a control. All the barrels had a broad top hole, which was covered by a cloth to prevent the inadvertent introduction of insects, dust, etc. The acetifications in each wood were done by triplicate.

The vinegar mothers were produced using both plants' own acetifying vinegars mixed with wine and water in a proportion of 25:50:25. These vinegar mothers (10\%) mixed with diluted wine were the initial mixture for the acetification process. The alcohol content of these mixtures was $11.3 \%$ (MG) and 9.5\% (LG) and the acetic acid content was $9 \mathrm{~g} / \mathrm{L}$ in both vinegar plants.

Acetic acid was determined by titration with $\mathrm{NaOH}$ and reducing sugars and ethanol with enzymatic kits (Boehringer Mannheim, Mannheim, Germany). Oxygen dissolved was measured using a LDO ${ }^{\mathrm{TM}} \mathrm{HQ} 10$ Portable Dissolved Oxygen Meter (HACH Company, Loveland, CO, USA).

Acetification rate ( $\mathrm{g}$ acetic $\mathrm{acid} / \mathrm{L}^{*}$ day) was the maximal slope obtained from the representation of acetic acid production towards acetification time.

\section{Statistical analysis}

We evaluated the effect of the vinegar plant and wood type and thickness using a three-way ANOVA with Sheffe's and b-Tukey's post hoc tests (except for vinegar plant variable since we had only two values). All statistical analyses were performed using SPSS version 15.0 for Windows (SPSS Inc., Chicago, IL, USA). A suitable control was considered for each variable. For the vinegar plant effect, the control was LG. For the wood type and thickness, the controls were oak and $25 \mathrm{~mm}$, respectively.

\section{Results}

All the barrels used in this study were new and cleaned with warm water and allowed to equilibrate with young wine prior to use. The research design set out to analyze two variables: wood type and thickness. As a general criterion we considered final acetification at $60 \mathrm{~g}$ acetic $\mathrm{acid} / \mathrm{L}$.

\section{Wood type \\ La Guinelle}

The differences found between wood types were minimal when process duration was compared in woods of the same thickness (Figure 1). In $15 \mathrm{~mm}$ barrels, wood type did not 
have any discernible effect on the vinegar production, with the exception of the chestnut barrels in which stuck acetification occurred in the last stages of the process. Complete acetification took 79 days.

Some differences between wood types were found in $20 \mathrm{~mm}$ barrels. In acacia barrels the process took the shortest amount of time (49 days) and in oak the longest (76 days). At $25 \mathrm{~mm}$, all wood types allowed for faster acetification (49 days) except oak, in which acetification was slower ( 76 days). Therefore, in this thickness the use of woods other than oak would reduce process time by approximately one third.

\section{Mas d'en Gil}

When the same processes were carried out in the other vinegar plant, no differences were found according to wood type (Figure 2). Similar acetification evolution and development was observed in all cases. It is important to mention that in this vinegar plant we found a clear decrease in the acetification rate when acetic acid values were near five degrees, which ultimately resulted in stuck acetification in all woods and thicknesses. The acetification processes required to achieve six-degree acetic acid were therefore very lengthy at around 250 days.
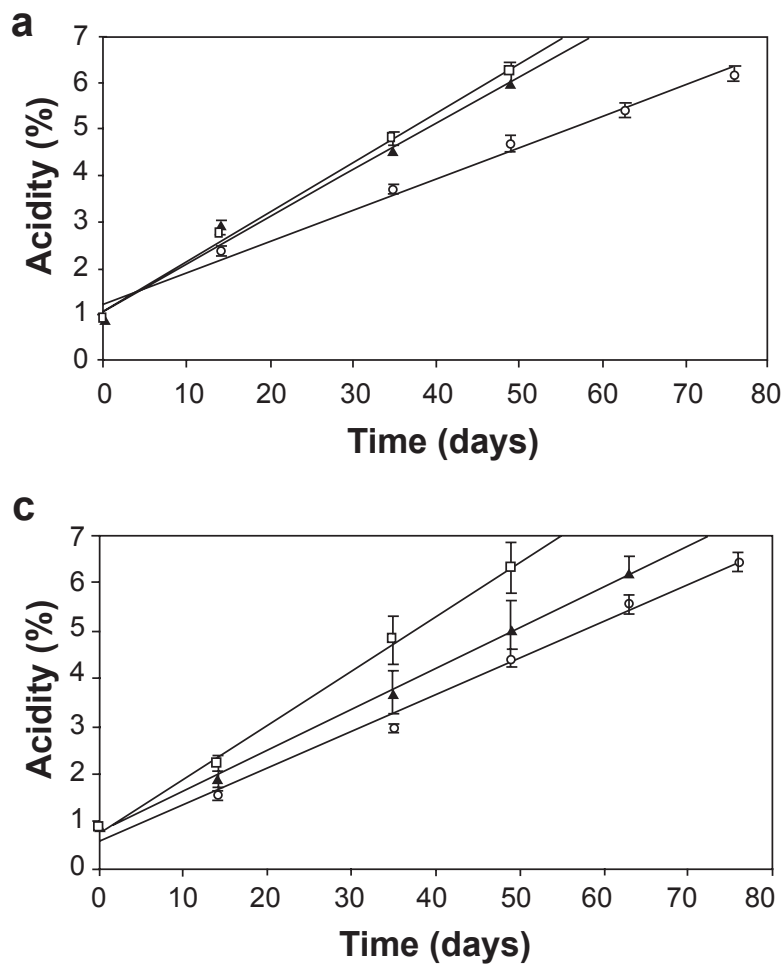

\section{Wood thickness}

\section{La Guinelle}

In general a thickness of $25 \mathrm{~mm}$ exhibited the fastest acetification (46 days) in all wood types except for oak, in which all acetification, regardless of barrel thickness, presented the same slow behaviour (76 days) (Figure 1). So, with the exception of oak, the effect of thickness on acetification velocity was contrary to the expected effect; the acetification rate slowed as barrel thickness decreased. The use of $15-\mathrm{mm}$-thick barrels resulted in a 35\% increase in acetification time over typical casks $(25 \mathrm{~mm})$.

\section{Mas d'En Gil}

No differences were observed in acetification as a result of barrel thicknesses; the same amount of time was required to complete the process in all cases (Figure 2).

\section{Acetification rate}

Significant differences emerged when comparing the acetification rate at the two vinegar plants, with the exception of oak at $25 \mathrm{~mm}$ (Table 1). Acetification at LG occurred faster and the complete process consequently required less time than at MG (Figures 1 and 2).
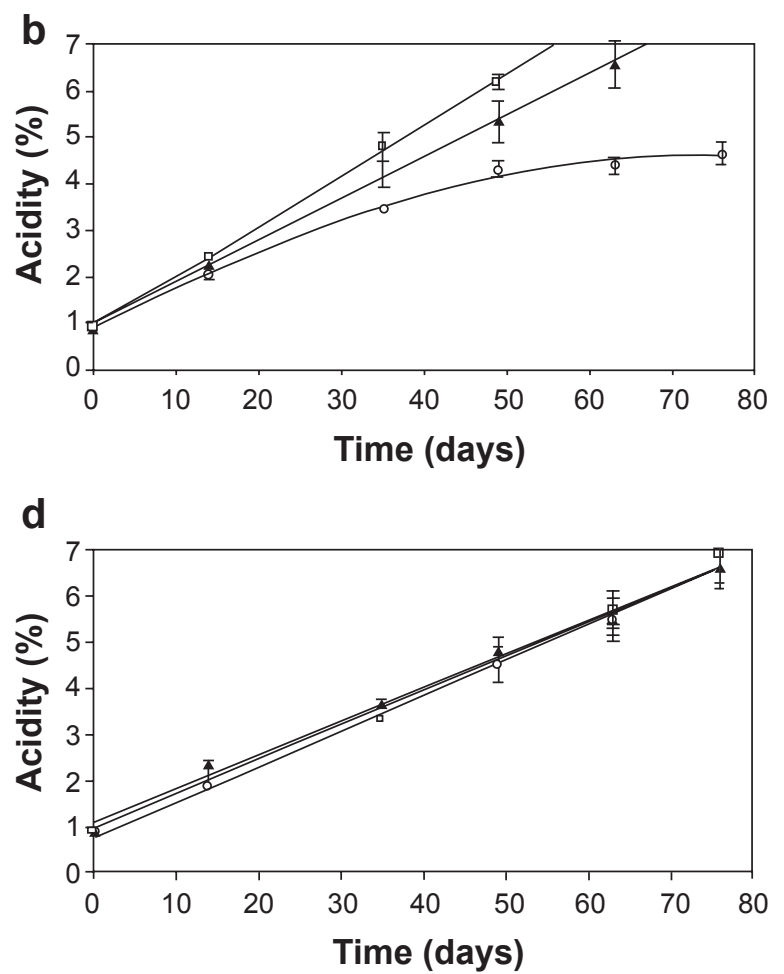

Figure I Variation of acidity in wood barrels (a, acacia; b, chestnut; $\mathbf{c}$, cherry; and d, oak) during acetification process according to the different thicknesses $(\diamond$ I5 mm barrels; - $20 \mathrm{~mm}$ barrels; $\square 25 \mathrm{~mm}$ barrels) in La Guinelle vinegar plant. The acidity values fitted to a linear regression except in chestnut I5 mm where a polinomic regression fit was needed. 

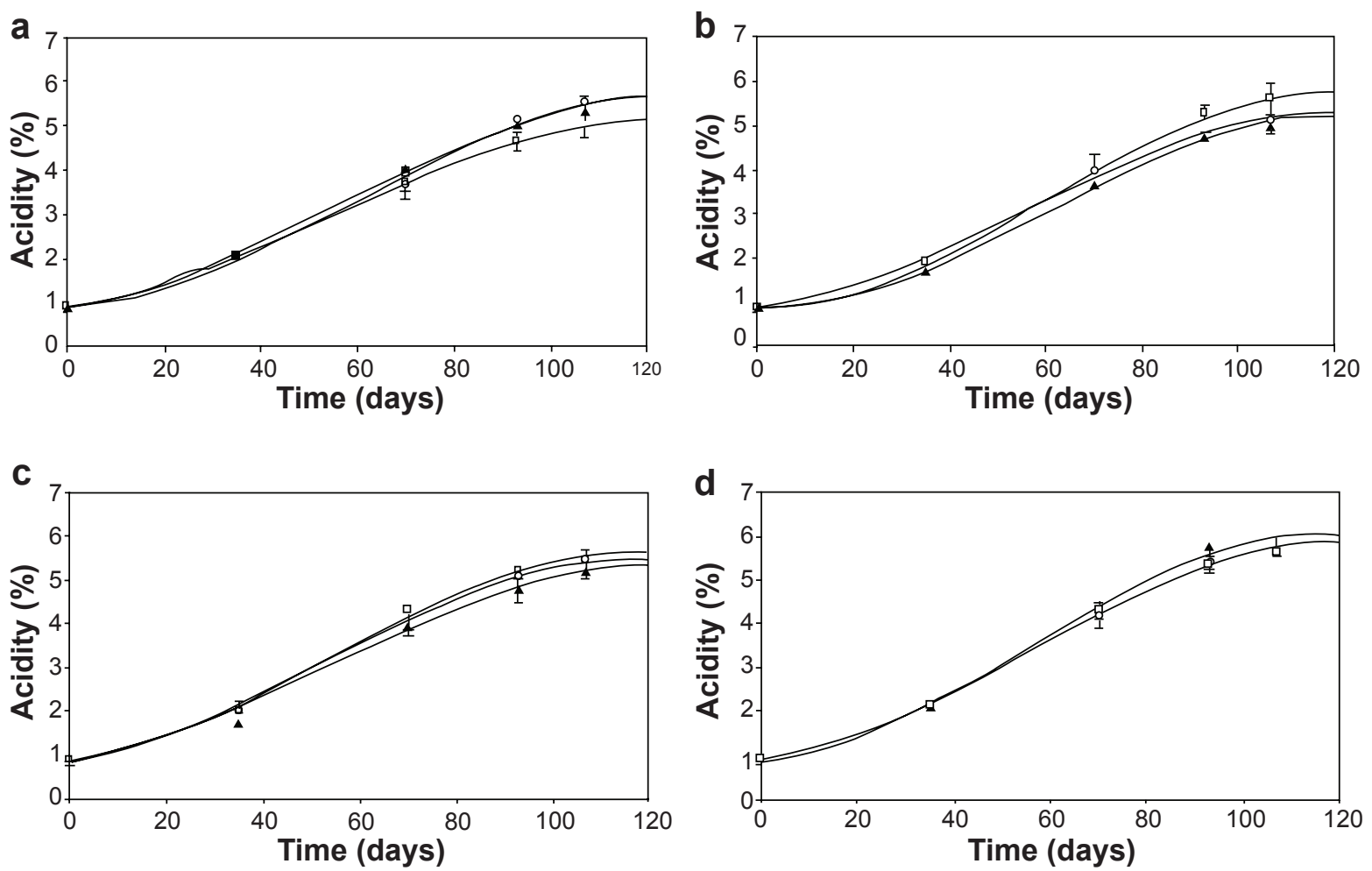

Figure 2 Variation of acidity in wood barrels (a, acacia; b, chestnut; c, cherry; and d, oak) during acetification process according to the different thicknesses ( $\diamond$ I5 mm barrels; $\Delta 20 \mathrm{~mm}$ barrels; $\square 25 \mathrm{~mm}$ barrels) in Mas d'en Gil vinegar plant. The acidity values fitted to a polinomic regression. The figure shows the exponential acetification until the process was stuck.

The acetification rate at MG was practically identical in the 36 processes studied, while acetification at LG showed interesting differences (Table 1). In all thicknesses, acacia presented the fastest acetification rate. In fact, this wood presented a significantly different acetification rate with respect to the control wood (oak) both in 20 and $25 \mathrm{~mm}$. On the other hand, $15 \mathrm{~mm}$ barrels accounted for the slowest acetification rate, except in oak where surprisingly, $25 \mathrm{~mm}$ barrels were the slowest, although these values only were statistically different in the case of acacia. It is important to remark that in some cases, the acetification rate at $20 \mathrm{~mm}$ (oak and acacia) was significantly higher than the one at $25 \mathrm{~mm}$ (control thickness), although this fact was not matched by a faster process.

\section{Discussion}

In this study, two variables related to increasing oxygen diffusion through the barrel were tested as possible ways to reduce the time required for the production of traditional wine vinegar. The parameters studied were wood type and thickness.

The barrels used for aging wine are usually made of oak. ${ }^{17,18}$ In the wine-aging process, oxygenation is limited in order to prevent spoiled aerobic microorganisms such as AAB from developing. ${ }^{19}$ Oak is well known for its limited porosity and permeability and is therefore a very suitable wood in which to age wine. However, vinegar production requires oxygen during the process to facilitate $\mathrm{AAB}$ development and the transformation of ethanol into acetic acid. Therefore, the common practice of using recycled wine barrels for the production of vinegar is clearly counterproductive. Wine barrels are made from oak, a wood that is not very porous to begin with and even less so after being used for aging wine, a process which causes most of the wood's pores to become clogged with tartrates and other sediments generated during wine processing. For these reasons, strategies to improve oxygen transfer are the most viable for shortening the acetification process.

In this study, both of the variables proposed were evaluated in two vinegar plants and the duration of the process and acetification rate were analyzed.

Comparing the two plants, acetification at LG was clearly faster than at MG and in the latter no differences were found between the conditions tested. This different acetification development between vinegar plants could be explained by differences in the microbiota responsible 
Table I Comparison of acetification rate ( $\mathrm{R} \pm \mathrm{SD}$; g acetic acid/L* day) considering different woods and thicknesses in both vinegar plants

\begin{tabular}{llll}
\hline Wood & $\begin{array}{l}\text { Thickness } \\
(\mathbf{m m})\end{array}$ & Vinegar plant \\
\cline { 3 - 4 } & & LG & MG \\
\hline Acacia & 15 & $1.03 \pm 0.06^{\mathrm{a}}$ & $0.47 \pm 0.07^{\mathrm{c}}$ \\
& 20 & $1.46 \pm 0.06^{\mathrm{a}, \mathrm{b}}$ & $0.47 \pm 0.04^{\mathrm{b}, \mathrm{c}}$ \\
& 25 & $1.29 \pm 0.00^{\mathrm{b}}$ & $0.59 \pm 0.09^{\mathrm{c}}$ \\
Chestnut & 15 & $0.82 \pm 0.06$ & $0.60 \pm 0.07^{\mathrm{c}}$ \\
& 20 & $1.00 \pm 0.16$ & $0.56 \pm 0.00^{\mathrm{c}}$ \\
& 25 & $1.14 \pm 0.14$ & $0.53 \pm 0.02^{\mathrm{c}}$ \\
Cherry & 15 & $0.84 \pm 0.06$ & $0.54 \pm 0.02^{\mathrm{c}}$ \\
& 20 & $0.89 \pm 0.06$ & $0.54 \pm 0.05^{\mathrm{b}, \mathrm{c}}$ \\
& 25 & $1.24 \pm 0.22^{\mathrm{b}}$ & $0.64 \pm 0.04^{\mathrm{c}}$ \\
Oak & 15 & $0.89 \pm 0.06$ & $0.59 \pm 0.07^{\mathrm{c}}$ \\
& 20 & $1.03 \pm 0.06^{\mathrm{a}}$ & $0.66 \pm 0.05^{\mathrm{c}}$ \\
& 25 & $0.76 \pm 0.09$ & $0.61 \pm 0.07$ \\
\hline
\end{tabular}

Notes: aSignificant differences due to the wood thickness using $25 \mathrm{~mm}$ as control; bSignificant differences due to the wood type using oak as control; 'Significant differences due to the vinegar plant using $L G$ as control.

Abbreviations: LG, La Guinelle; MG, Mas d'en Gil; SD, standard deviation.

for the process and in the wine used for acetification. It is well established that different AAB strains can present differences in tolerance to ethanol and acetic acid and in the efficiency of transforming ethanol into acetic acid. ${ }^{20}$ In our case, indigenous $\mathrm{AAB}$ strains from LG clearly seemed to be better adapted to the process conditions than the MG strains, and this is reflected in a higher transformation rate at LG. Furthermore, the composition of the initial media also determines which species and strains of $\mathrm{AAB}$ are capable of growing throughout the process. ${ }^{21}$ In our case, the wine used in $L G$ acetification was rich in residual sugars while the MG wine was dry and presented a higher content of ethanol, which could explain the MG acetification problems.

Acetification at MG, which was slower, presented no differences based on wood type or thickness whereas the same process done at LG, which resulted in faster acetification, presented some clear differences according to wood type and thickness. One possible explanation might be related to the ethanol transformation rate. In theory, for faster acetification to occur more oxygen is required over a short time, and different strains have different oxygen needs. Therefore, we hypothesized that in slow acetification, where a slow conversion of ethanol into acetic acid occurred, AAB oxygen needs were covered by atmospheric oxygen and therefore no differences were observed based on wood porosity, as in the case of the MG acetification. However, when rapid acetification occurred, this fast transformation of ethanol into acetic acid required more oxygen, which became the limiting substrate. Therefore, the amount of oxygen provided through the barrel could account for differences in acetification. Thus, in these cases, wood porosity may determine the time needed to complete the acetification process when the conversion of ethanol into acetic acid is suitably efficient. In fact, the concentration of dissolved oxygen throughout the process was minimal in all acetification $(0.04-0.09 \mathrm{mg} / \mathrm{mL})$, except during the stuck acetifications where an accumulation of oxygen was detected $(0.96-2.34 \mathrm{mg} / \mathrm{mL})$. This indicates that while $\mathrm{AAB}$ was active, all the oxygen was being used for vinegar production and $\mathrm{AAB}$ development.

Focusing on the LG results, we were surprised that reducing the thickness of the wood barrel did not improve the process in any case and even had a negative effect on the acetification rate and process duration. The explanation for why in these conditions a thicker barrel was better is completely unknown, and with our results attempting to explain why reduced thickness did not improve the acetification process would be too speculative.

On the other hand, the effect of wood type was consistent with its porosity. In fact, it is known that oxygen diffusion through wood is higher in less compact woods ${ }^{14}$ such as acacia and chestnut. In the case of the $25 \mathrm{~mm}$ casks, the control for thickness, the worst wood was oak, so the choice of the wood for vinegar-aging barrels must be a compromise between increased porosity to accelerate the process and the effect that the wood has on vinegar quality.

In this study, we tested two variables related to increasing oxygenation during the vinegar production process. Although the type of wood in which the product was aged seemed to have more importance than the thickness of the barrel, perhaps the best solution is to increase the surface/volume ratio, thereby increasing the contact between $\mathrm{AAB}$ and atmospheric oxygen, since the amount of oxygen provided through the barrel seems to be limited.

\section{Acknowledgments}

The authors are grateful for financial assistance from the Spanish Government (Project AGL2007-66417-C02-02) and the European Commission (Project WINEGAR, Cooperative Research under the Sixth Framework Programme of the European Community, 2005-2007). We thank the Language Service of the Rovira i Virgili University for revising the manuscript. 


\section{Disclosure}

The authors report no conflicts of interest in this work.

\section{References}

1. Llaguno C. Antecedentes históricos. In: Llaguno C, Polo MC, editors. El vinagre de vino. Madrid, Spain: CSIC; 1991; p. 1-23.

2. Adams MR. Vinegars. In: Wood BJB, editor. Microbiology of fermentated foods. 2nd ed. London, UK: Thomson Science; 1998. p. $1-44$.

3. Tesfaye W, Morales ML, García-Parrilla MC, Troncoso AM. Wine vinegar: technology, authenticity and quality evaluation. Trends Food Sci Technol. 2002;13(1):12-21.

4. Mas A, Torija MJ, González A, Poblet M, Guillamón JM. Acetic acid bacteria in oenology. Contributions to Science. 2007;3(4):511-521.

5. Caligiani A, Silva G, Palla G. Determination of 2,3-butanediol and 2-hydroxybutanone stereoisomers in batteries of tradicional Balsamic vinegar. J Agric Food Chem. 2007;55:7810-7815.

6. Gonzáles-Viñas MA, Salvador MD, Cabezudo MD. Taste group thresholds and sensory evaluation of Spanish wine vinegars. J Sens Stud. 1996;11:129-140.

7. Tesfaye W, Morales ML, Benítez B, García-Parrilla MC, Troncoso AM. Evolution of wine vinegar composition during accelerated aging with oak chips. Anal Chim Acta. 2004;513:239-245.

8. Waterhouse AL, Towey JP. Oak lactone isomer ratio distinguishes between wines fermented in American and French oak barrels. J Agric Food Chem. 1994;42:1971-1974.

9. Spillman PJ, Pollnitz AP, Liacopoulos D, Skouroumounis GK, Sefton MA. Accumulation of vanillin during barrel aging of white, red and model wines. J Agric Food Chem. 1997;45:2584-2589.

10. Sauvageot F, Feuillat F. The influence of oak wood (Quercus robur L., Q. petraea Liebl.) on the flavor of Burgundy Pinot noir. An examination of variation among individual trees. Am J Enol Vitic. 2000;50:447-455.
11. Fernández de Simón B, Cadahía E, Galocha J. Volatile compounds in a Spanish red wine aged in barrels made of Spanish, French, and American oak wood. J Agric Food Chem. 2003;51:7671-7678.

12. Ortega-Heras M, González-Huerta C, Herrera P, González-Sanjosé ML. Changes in wine volatile compounds of varietal wines during ageing in wood barrels. Anal Chim Acta. 2004;513:341-350.

13. Arfelli G, Santini E, Corzani C, Fabiani A, Natali N. Impact of wooden barrel storage on the volatile composition and sensorial profile of red wine. Food Sci Technol Int. 2007;13(4):293-299.

14. Ribéreau-Gayon P, Dubourdieu D, Donèche B, Lonvaud A. Handbook of Enology. The microbiology of wine and vinifications. West Sussex, England: Wiley; 2000.p. 183-192.

15. Morales ML, Tesfaye W, García-Parrilla MC, Casas JA, Troncoso AM. Evolution of the aroma profile of Sherry wine vinegars during an experimental aging in wood. J Agric Food Chem. 2002;50(11):3173-3178.

16. Callejón RM, Tesfaye W, Torija MJ, Mas A, Troncoso AM, Morales ML. Volatile compounds in red wine vinegars obtained by submerged and surface acetification in different woods. Food Chem. 2009;113:1252-1259.

17. Singleton VL. Maturation of wines and spirits: comparisons, facts, and hypotheses. Am J Enol Vitic. 1995;46(1):98-115.

18. Hernández T, Estrella I, Dueñas M, Fernández de Simón B, Cadahía E. Influence of wood origin in the polyphenolic composition of a Spanish red wine aging in bottle, after storage in barrels of Spanish, French and American oak wood. Eur Food Res Technol. 2007;224:695-705.

19. Joyeux A, Lafon-Lafourcade S, Ribéreau-Gayon P. Evolution of acetic acid bacteria during fermentation and storage of wine. Appl Environ Microbiol. 1984;48(1):153-156.

20. De Ley J, Gosselé F, Swings J. Genus I. Acetobacter. In: Kreig NR, Holt JC, editors. Bergey's Manual of Systematic Bacteriology. Vol. 1. Maryland: Williams and Wilkens; 1984. p. 268-274.

21. Callejón RM, Tesfaye W, Torija MJ, Mas A, Troncoso AM, Morales ML. HPLC determination of amino acids with AQC derivatization in vinegars along submerged and surface acetifications and its relation to the microbiota. Eur Food Res Technol. 2008;227:93-102.
International Journal of Wine Research

\section{Publish your work in this journal}

The International Journal of Wine Research is an international, peer-reviewed open-access, online journal focusing on all scientific aspects of wine, including: vine growing; wine elaboration; human interaction with wine; and health aspects of wine. The journal provides an open access platform for the reporting

\section{Dovepress}

of evidence based studies on these topics. The manuscript management system is completely online and includes a very quick and fair peer-review system, which is all easy to use. Visit http://www.dovepress.com/testimonials.php to read real quotes from some of our published authors. 